\title{
The bioavailability of non-nutrient plant factors: dietary flavonoids and phyto-oestrogens
}

\author{
Helen Wiseman \\ Department of Nutrition and Dietetics, King's College London, Campden Hill Road, Kensington, London W8 7AH, UK
}

\begin{abstract}
The bioavailability in human subjects of non-nutrient plant factors, including dietary flavonoids and phyto-oestrogens, is of great importance relative to their reported health protective effects. These effects include protection against heart disease, and also in the case of the phyto-oestrogens, hormone-dependent cancers. Epidemiological studies have shown flavonoid intake (mostly quercetin) to be inversely associated with mortality from CHD. Quercetin is a potent antioxidant in vitro, and protection against the oxidative damage to LDL implicated in atherogenesis has been suggested as a possible mechanism. Human subjects can absorb significant amounts of quercetin (particularly in the glucoside form) and it would appear to be sufficiently bioavailable to act as an antioxidant in vivo; however, following our recent study (J O'Reilly, TAB Sanders and H Wiseman, unpublished results), it is currently less clear whether quercetin really can act as an antioxidant in vivo. The isoflavone phyto-oestrogens genistein and daidzein are much less effective antioxidants than quercetin in vitro, however, they are well-absorbed by human subjects and appear to be sufficiently bioavailable to act as antioxidants in vivo. In our recent study (O'Reilly et al. 1998) lower plasma isoprostane concentrations and increased resistance of LDL to oxidation were observed following the high-isoflavone dietary phase compared with the lowisoflavone dietary phase. Considerable inter-individual variation in isoflavone metabolite excretion has been observed, in particular the production of equol (the gut bacterial metabolite of daidzein; a more potent antioxidant and more oestrogenic than daidzein), and this appears to be influenced by habitual diet. Further studies on the bioavailability of these non-nutrient plant factors and related influencing factors are clearly still required.
\end{abstract}

Phyto-oestrogens: Flavonoids: Bioavailability: Antioxidants: Heart Disease: Cancer

Non-nutrient plant factors, including the dietary flavonoids and phyto-oestrogens, are currently being investigated to determine their importance in the prevention of major diseases, including heart disease and cancer. Flavonoids, in particular the flavonol quercetin (Cook \& Saman, 1996; Hertog \& Hollman, 1996; Wiseman, 1998), and phytooestrogens (Adlercreutz et al. 1995; Adlercreutz, 1996; Cassidy, 1996; Wiseman, 1996, 1997, 1998; Bingham et al. 1998; Williams \& Rutledge, 1998) such as the isoflavones genistein and daidzein, are the main focus of the present article. Some members of the flavonoid family, including the isoflavonoids and some of the flavones and flavanones, also belong to the phyto-oestrogen family (non-steroidal oestrogen-mimics derived from plants), which also includes a number of chalcones, coumestans, stilbenes and lignans (Wiseman, 1998). In general, most flavonoids are present in plants in their glycoside form, whereas the unconjugated (aglycone) forms demonstrate far greater oestrogenic activity (Miksicek, 1995). The present article thus examines the importance of obtaining a measure of the bioavailability of such non-nutrient plant factors in order to assess fully their biological effects.

\section{Factors influencing bioavailability of dietary factors}

An estimate of the absolute bioavailability (expressed as a percentage) of a non-nutrient plant factor from a food source is derived from knowledge of the proportion of molecules that enter the blood circulation intact after consumption and following their passage across the gut wall and their first passage through the liver. Bioavailability is thus not indicated entirely by the extent of absorption. Absorption, distribution, metabolism (bioconversion in the gut and biotransformation in the liver) and elimination all contribute 
to the bioavailability and subsequent effectiveness of a nonnutrient plant factor following ingestion. Bioavailability thus quantifies the exposure of the body (not including the liver or the gut) to the non-nutrient plant factor in question (Hollman, 1997a). Absolute bioavailability can be determined experimentally by administering the flavonoid, for example, both orally and intravenously, and then calculating the ratio of plasma levels with time (from the areas under the curve). The studies in human subjects described here did not include intravenous administration of flavonoids or phyto-oestrogens, and thus only provide information on the relative bioavailability of the non-nutrient plant factor in different foods (Hollman, 1997a; Hollman et al. $1997 a, b)$. The bioavailability of dietary flavonoids and phyto-oestrogens is clearly important in assessing the likely importance of these compounds to human health. Until recently, relatively little information has been available on the absorption and subsequent distribution, metabolism and excretion in human subjects of non-nutrient plant factors (including the flavonoids and phyto-oestrogens) which will invariably influence their bioavailability. It was originally suggested that flavonoids derived from foods could not be absorbed from the small intestine because, with the exception of catechins, they are found attached to sugars (as glycosides) which were considered to be non-absorbable from the intestine (Hollman, 1997a,b). It was considered possible for the aglycones (free flavonoid without a sugar molecule) to be taken up from the gut, but no enzymes capable of liberating free aglycones are present in the intestinal wall (or secreted into the gut). Hydrolysis of the mostly $\beta$-glycosidic bonds that attach flavonoid to sugars takes place only in the colon, where it is mediated by the micro-organisms that can also extensively degrade the flavonoid molecule (Hollman, 1997a,b).

\section{Bioavailability of the flavonol quercetin}

Flavonols include quercetin, found in onions (Allium cepa), and to a lesser extent in French beans (Phaseolus vulgaris), broad beans (Vicia faba), apples, apricots, cherries, grapes, wine, fruit juices, black tea and green tea (Hertog et al. 1992, 1993b,c; Crozier et al. 1997). Green tea is a major dietary source of the catechins, which include catechin, epicatechin, epigallocatechin and epigallocatechin gallate (Cook \& Saman, 1996; Hollman, 1997b). Grapes and other highly-pigmented fruits are good sources of anthocyanidins, which are responsible for the colour and include cyanidin and pelargonidin (Hollman, 1997b).

A dietary study with healthy ileostomy patients (thereby avoiding losses caused by colonic bacterial degradation) has shown that human subjects can in fact absorb significant amounts of quercetin, and that glycosides can be absorbed from the small intestine (Hollman et al. 1995, 1997b). Absorption of quercetin glucosides was $52 \%$, absorption of pure quercetin was $24 \%$ and that of quercetin rutinoside was $17 \%$ (Hollman et al. 1995, 1997b). This not only shows that the glycone form of quercetin can be absorbed, but also that absorption of the glucoside is greater than that of both the aglycone and the rutinoside; thus, absorption is enhanced by conjugation with glucose. A number of flavonoid glycosides, including quercetin rutinoside (rutin), other quercetin glycosides (as yet unidentified) and phloridzin, have all been detected in the plasma of unsupplemented subjects, in the range 0.5-1.6 $\mathrm{M}$ (Paganga \& Rice-Evans, 1997).

The exact influence of the sugar group on the absorption of quercetin glycosides has been investigated, and the much more rapid and greater rise in plasma quercetin levels following ingestion of the glucoside compared with the rutinoside suggests that the former may be rapidly absorbed directly from the small intestine, in contrast to the latter which is probably absorbed only from the colon (Hollman, 1997a). A role for the $\mathrm{Na}$-glucose co-transporter (located in the brush-border membranes of the small intestine) in the absorption of quercetin $4^{\prime}$-glucoside has been proposed (Hollman, 1997a).

The kinetics of the absorption and disposition of quercetin has been studied in human subjects (Hollman et al. 1996; Hollman, 1997a). After $2.9 \mathrm{~h}$ peak plasma levels of quercetin of $196 \mathrm{ng} / \mathrm{ml}$ were reached. The half-life of quercetin absorption was $0.87 \mathrm{~h}$, and those of the distribution and elimination phases were 3.8 and $16.8 \mathrm{~h}$ respectively. The plasma concentration decreased to approximately $10 \mathrm{ng} / \mathrm{ml}$ after about $48 \mathrm{~h}$, suggesting that quercetin glycosides from onions are absorbed and eliminated at quite a gradual rate (Hollman et al. 1996; Hollman, 1997a). Quercetin has also been shown to be extensively metabolized; less that $1.5 \%$ of the ingested quercetin excreted in urine had an intact flavonoid structure (Hollman et al. 1995, 1997b).

The accumulation in plasma and excretion in urine of flavonol glucosides following the consumption of lightly-fried yellow onions by healthy subjects has been investigated and has been found to be greater for isorhamnetin- $4^{\prime}-O-\beta$ glucoside compared with quercetin-4'-O- $\beta$-glucoside, indicating again that flavonols are absorbed as glucosides, and demonstrating that small structural differences can have a major effect on absorption and excretion (Aziz et al. 1998).

In order to determine the relative bioavailability of quercetin from different food sources, the time-course of the plasma quercetin concentration has been measured following single doses of onions or apples (Hollman, 1997a; Hollman et al. 1997a). Black tea is another good dietary source of quercetin; the major glycosides present in tea leaves are the 3-rutinoside (50\%), the 3-glucoside (30\%) and the 3-galactoside $(20 \%)$. However the low quercetin concentrations of actual tea infusions meant that pure quercetin rutinoside, selected as the representative tea glycoside of quercetin, was best administered in capsule form. The bioavailability of pure quercetin rutinoside and of the form of quercetin found in apples was $30 \%$ relative to that of the form of quercetin found in onions. This suggests that the type of sugar group of the glycoside has a great influence on absorption (Hollman, 1997a; Hollman et al. 1997a).

\section{Importance of quercetin bioavailability for health protective effects}

In the Zutphen Elderly Study (Hertog et al. 1993a; Keli et al. 1996) the mean baseline flavonoid intake was $25.9 \mathrm{mg}$ 
and the major sources of intake were tea $(61 \%)$, onions $(13 \%)$ and apples $(10 \%)$. Flavonoid intake, which was analysed in tertiles, was significantly inversely associated with mortality from CHD. This study also provided evidence for flavonoid-mediated protection against stroke; dietary flavonoid content (in particular quercetin) was inversely associated with stroke incidence (Keli et al. 1996). The average intake of quercetin in The Netherlands is $16 \mathrm{mg} / \mathrm{d}$ and this is provided mostly by tea (48\%), onions (29\%) and apples (7\%) (Hertog et al. 1993b). The contribution of quercetin to the total flavonol plus flavone consumption has been determined to be $68-73 \%$ in freeliving subjects from fourteen different countries eating a variety of diets (average total flavonoid intake $27.6 \mathrm{mg} / \mathrm{d}$ ), and the major sources of intake were (\%): tea 37 , onions 26 , vegetables 14, fruit 22, red wine 1 (de Vries et al. 1997). However, flavonoid intake did not appear to influence cancer mortality in the Zutphen Elderly Study (Hertog et al. 1994), and this is in contrast to the anti-carcinogenic effects observed in animal models and in human cancer cells in vitro (Hertog \& Hollman, 1996).

It thus appears possible that consumption of quercetinrich foods can result in significant plasma quercetin levels that could contribute to the plasma antioxidant capacity. The long half-life of elimination ( $24 \mathrm{~h}$ ) is independent of the type of glycoside of quercetin and suggests that quercetin will accumulate in plasma; steady-state levels of $0.2 \mu \mathrm{M}$ can be achieved (Hollman, 1997a; Hollman et al. 1997a,b). This concentration can be achieved after consumption of onions containing $30 \mathrm{mg}$ quercetin. This corresponds to the intake in the highest tertile in the Zutphen Elderly Study, where risk of CHD was substantially reduced (Hertog et al. $1993 a$ ).

A number of mechanisms have been proposed for the protection conferred against CHD by flavonoids, including their antioxidant activity. Oxidative damage to LDL, particularly to the apoprotein B molecule, is considered to be an important stage in the development of atherosclerosis (Steinberg et al. 1989). Flavonoids such as quercetin are effective inhibitors of in vitro oxidative modification of LDL by macrophages or by $\mathrm{Cu}$ ions (De Whalley et al. 1990). The concentration of quercetin reported in plasma $(0.2 \mu \mathrm{M})$ may be able to protect $\mathrm{LDL}$ against oxidative modification. Indeed, quercetin can inhibit LDL oxidation in vitro, with a value of $0.5 \mu \mathrm{M}$ for the inhibitory concentration giving $50 \%$ maximal oxidation ( $\mathrm{J}$ O'Reilly and $\mathrm{H}$ Wiseman, unpublished results). It is interesting, therefore, that our recent randomized crossover study in human subjects does not appear to indicate any overall changes in the biomarkers of oxidative damage measured, including resistance of LDL to oxidation, between the low- and highflavonoid dietary phases (J O'Reilly, TAB Sanders and H Wiseman, unpublished results).

\section{Bioavailability of the isoflavone and lignan phyto-oestrogens}

The isoflavonoids include the isoflavone phyto-oestrogens genistein and daidzein, which occur mainly as glycosides of the parent aglycone in soyabeans, and consequently in a wide range of soyabean-derived products, and to a lesser extent in other legumes (Reinli \& Block, 1996). Soya foods traditionally made from soyabeans include both fermented and non-fermented foods (Golbitz, 1995). Some alcoholic beverages such as beer have been shown to contain significant amounts of isoflavonoid phyto-oestrogens (Lapcik et al. 1998). Lignans are non-flavonoid dietary phytooestrogens which are found as the plant precursors (secoisolariciresinol and matairesinol) of the mammalian lignans enterodiol and enterolactone. Secoisolariciresinol and matairesinol are found in linseed and sesame seed respectively, and both are found also in a number of whole grains (Thompson, 1994; Slavin et al. 1997).

Following ingestion, daidzin and genistin are hydrolysed in the large intestine by the action of bacteria to release genistein and daidzein. Daidzein can be metabolized by the bacteria in the large intestine to form equol (oestrogenic) or $O$-desmethylangolensin (non-oestrogenic), whereas genistein is metabolized to the non-oestrogenic p-ethyl phenol. Inter-individual variation in ability to metabolize daidzein to equol could thus influence the potential health protective effects of soyabean isoflavones (see p. 143). The lignan phyto-oestrogen precursors in plant material, matairesinol and secisolariciresinol, are converted by gut bacteria to the two main mammalian lignans (health factors) enterolactone and enterodiol respectively (Thompson, 1994). Matairesinol undergoes dehydroxylation and demethylation directly to enterolactone, whereas secisolariciresinol is converted to enterodiol, which can then be oxidized to enterolactone (Adlercreutz, 1996). After absorption, enterolactone and enterodiol are excreted in urine (see later), although relatively limited studies of the metabolism of lignans in human subjects have been carried out. A study in ileostomists found (in the absence of sufficient bacterial activity for conversion of plant lignans to mammalian lignans) no increase in plasma levels of mammalian lignans (Pettersson et al. 1996).

The urinary excretion of phyto-oestrogens can be used as a measure of intake, and hence possible exposure of tissues to bioavailable phyto-oestrogens which could confer protection against cancer. In assessing exposure to the protective effects of phyto-oestrogens, urinary excretion rates should be considered in combination with the plasma levels attained. A very low urinary excretion of lignans and equol (isoflavan metabolite of the isoflavone daidzein) has been observed in post-menopausal breast cancer patients compared with vegetarians (Adlercreutz et al. 1995; Adlercreutz, 1996). In human subjects, omnivorous subjects usually have low levels of isoflavonoid excretion, and in individuals consuming a Western diet, urinary levels of lignans have been found to be greater than those of isoflavones (Adlercreutz et al. 1995; Adlercreutz, 1996).

Urinary excretion of the lignans enterodiol and enterolactone was elevated in subjects consuming a carotenoidvegetable diet and a cruciferous-vegetable diet compared with the basal (vegetable-free) diet, suggesting these vegetables may provide a source of mammalian lignan precursors (Kirkman et al. 1995). In addition, men excreted less enterodiol and more enterolactone compared with women, suggesting there may be a sex difference in the bacterial metabolism of lignans in the colon (Kirkman et al. 1995). Urinary excretion of genistein, daidzein, equol and 
$O$-desmethylangolensin was found to be greater in subjects when they consumed a soyabean-rich diet compared with vegetable-rich (carotenoid $v$. cruciferous) and basal (vegetable-free) diets (Kirkman et al. 1995). Young American women from different ethnic groups have been found to predominantly excrete different types of phytooestrogens in their urine, and presumably this reflects cultural influences on the diets consumed (Horn-Ross et al. 1997). Urinary isoflavonoid excretion has been reported to be dose-dependent at low to moderate levels of soyabean consumption (Karr et al. 1997).

In a study of plasma isoflavonoid levels in Japanese men compared with Finnish men, the means of the total daidzein, genistein, $O$-desmethylangolensin and equol levels were approximately 17-, 44-, 33- and 55-fold higher for the Japanese subjects compared with the Finnish subjects (Adlercreutz et al. 1993). In a study of postmenopausal Australian women consuming soyabean flour, mean plasma levels of daidzein and equol of 68 and $31 \mathrm{ng} / \mathrm{ml}$ respectively were observed (Morton et al. 1994). In some subjects, however, levels $(\mathrm{ng} / \mathrm{ml})$ as high as 148 for genistein, 43 for equol and 312 for daidzein were reached (Morton et al. 1994). Furthermore, only $33 \%$ of subjects were able to metabolize daidzein to equol. In addition, combined levels of enterolactone and enterodiol of $500 \mathrm{ng} / \mathrm{ml}$ were reached following linseed supplementation (Morton et al. 1994). In a study of the short-term metabolism of isoflavonoid and lignan phyto-oestrogen, male subjects ingested a cake containing soyabean flour and cracked linseed (Morton et al. 1997). Increased serum concentrations of both genistein and daidzein were observed within $30 \mathrm{~min}$ of consumption, with maximum concentrations reached by $5 \cdot 5-8.5 \mathrm{~h}$ following consumption. Maximum plasma concentrations were $87 \cdot 5-190 \mathrm{ng} / \mathrm{ml}$ for genistein and $83 \cdot 3-129 \mathrm{ng} / \mathrm{ml}$ for daidzein; none of the subjects was able to metabolize daidzein to equol. The metabolism of the plant lignans to the mammalian lignans was slower, with increased plasma levels of enterolactone and enterodiol found $8.5 \mathrm{~h}$ after consumption (Morton et al. 1997).

The plasma and urinary kinetics of daidzein and genistein have been determined in men following a single soyabean meal (soyabean-flour-based meal; King \& Bursill, 1998). The maximum plasma concentrations were approximately $3 \mu \mathrm{mol} / 1$ at approximately $7 \mathrm{~h}$ and $4 \mu \mathrm{mol} / 1$ at $8 \mathrm{~h}$ for daidzein and genistein respectively, and the corresponding elimination half-lives were approximately 5 and $6 \mathrm{~h}$ (King \& Bursill, 1998). A slow rise in plasma isoflavone concentrations was observed, which suggests that absorption is taking place following hydrolysis in the small and large intestines of the glycone forms of the isoflavones to their aglycone forms (King \& Bursill, 1998). Although the urinary excretion of daidzein was greater than that of genistein (recoveries of approximately 62 and $22 \%$ respectively), the ratio of the areas under the plasma concentration $v$. time curves for genistein and daidzein was equal to the ratio of the concentrations of the respective isoflavones in the soyabean meal. Overall, this study thus suggests that despite the differences in urinary excretion, the bioavailabilities of genistein and daidzein are in fact similar (King \& Bursill, 1998).
A variable metabolic response to isoflavones has been reported for subjects who consumed soyabean flour over $2 \mathrm{~d}$ (Kelly et al. 1995). Urinary levels of genistein, daidzein, equol and $O$-desmethylangolensin were elevated 8-, 4-, 45and 66-fold respectively over baseline following consumption. Considerable inter-individual variation in metabolic response was found, with the peak levels of equol showing the greatest variation (Kelly et al. 1995). An inverse relationship between equol and $O$-desmethylangolensin was observed, suggesting inter-individual variation in the dominant metabolic pathway for daidzein metabolism. This may be important in relation to cancer risk, as equol is much more oestrogenic than daidzein or $O$-desmethylangolensin (Kelly et al. 1995). The reasons for the wide inter-individual variation in isoflavone metabolite excretion following the consumption of soyabean have not been fully elucidated; however, in a recent study female equol excreters have been reported to consume a higher percentage of energy as carbohydrate and also greater amounts of plant protein and NSP (Lampe et al. 1998). In our recent randomized crossover dietary intervention study in healthy male and female subjects, a diet high in isoflavones (textured-soyabeanprotein product supplying $56 \mathrm{mg} / \mathrm{d}$ ) and a diet low in isoflavones (textured-soyabean-protein product supplying $2 \mathrm{mg} / \mathrm{d}$ ) were each consumed for 2 weeks separated by a 3 -week washout period. We found that good equol producers $(35 \%$ of subjects and defined as $>1000 \mathrm{nmol} / 24 \mathrm{~h}$ ) excreted about 200 -fold more equol in their urine than the poor equol producers, and consumed significantly less fat and more carbohydrate and also greater amounts of NSP compared with the poor equol producers (Bowey et al. 1999).

Chronic soyabean ingestion (as soyabean milk) appears to modulate the metabolism and disposition of ingested isoflavones in young females, and an increase in the production of equol was observed in some of the subjects (Lu et al. 1996). In contrast, in males, chronic soyabean exposure did not alter the pathways of isoflavone metabolism, but altered the time-courses of excretion ( $\mathrm{Lu}$ et al. 1995).

Metabolism by the gut microflora is an important factor influencing the disposition of chemicals in the gut, and can result in activation of substances to more-biologically-active products. The bioavailability of soyabean isoflavones has been shown to depend on the gut microflora in women (Xu et al. 1995). Differences in faecal excretion greatly influenced isoflavone bioavailability; urinary recovery of ingested isoflavone phyto-oestrogens was more than twice as high in high $v$. low faecal excreters (Xu et al. 1995). Gut bacterial enzymes such as $\beta$-glucuronidases can hydrolyse isoflavone conjugates to aglycones (rapidly re-absorbed). However, intestinal microflora can also extensively metabolize and degrade isoflavones and other flavonoids, thus preventing their re-absorption from the colon. If an individual possesses bacteria that are not effective in isoflavone metabolism and degradation then more isoflavones would be absorbed, which would explain the positive association between high faecal isoflavones and greater total urinary recovery of isoflavones (Xu et al. 1995).

The presence of different populations of microflora in the human gut may influence the bioavailability of soyabean 
isoflavone phyto-oestrogens. Our recent dietary intervention study with soyabean isoflavones has demonstrated considerable inter-individual variation in isoflavone phyto-oestrogen metabolism (Bowey et al. 1999: see p. 142) and significant effects on gut bacterial activity and gastrointestinal function (E Bowey, H Adlercreutz, I Rowland, TAB Sanders and H Wiseman, unpublished results). Studies on the types of human gut microflora involved in phyto-oestrogen bioavailability are needed. The metabolism of daidzein to equol by certain types of gut bacteria has important implications for daidzein bioavailability, because equol producers are likely to have lower levels of bioavailable daidzein. Equol has its own particular health benefits and concerns (i.e. it is a more potent oestrogen and antioxidant).

\section{Importance of bioavailability to the health protective action of phyto-oestrogens}

The incidence of breast and prostate cancer is much greater in Western countries than in Far Eastern countries, where there is an abundance of dietary phyto-oestrogens (Adlercreutz et al. 1995; Adlercreutz, 1996; Cassidy, 1996; Bingham et al. 1998). Lower levels of prostate cancer are also reported for vegetarians who consume large amounts of plant material (rich in lignans). Levels of isoflavonoids and lignans have been measured in prostatic fluid from males from different parts of the world (Morton et al. 1997) to determine the levels of bioavailable (and thus bioactive) phyto-oestrogens in body tissues. The highest mean levels of daidzein and its metabolite equol were found in males from Hong Kong (70 and $29.2 \mathrm{ng} / \mathrm{ml}$ respectively) and China $(24.2$ and $8.5 \mathrm{ng} / \mathrm{ml}$ respectively), compared with those in males from the UK $(11.3$ and $0.5 \mathrm{ng} / \mathrm{ml}$ respectively) and Portugal ( 4.6 and $1.72 \mathrm{ng} / \mathrm{ml}$ respectively). In contrast, the highest levels of lignans were found in prostatic fluid from men from Portugal (enterolactone $162 \mathrm{ng} / \mathrm{ml}$, enterodiol $13.5 \mathrm{ng} / \mathrm{ml}$ ). The levels of enterolactone and enterodiol were similar in prostatic fluid from men from the other countries investigated (enterolactone $20.3-32.9 \mathrm{ng} / \mathrm{ml}$, enterodiol $1.6-6 \mathrm{ng} / \mathrm{ml}$ ).

Analysis of human breast milk has detected conjugates of genistein and daidzein following the consumption of roasted soyabeans (France \& Custer, 1996). Thus, concentrations of daidzein and genistein of $20-28$ and $8-14 \mathrm{ng} / \mathrm{ml}$ respectively have been found in a subject who naturally consumed a diet rich in soyabean products and from another subject following a soyabean challenge. A preferential excretion of the main metabolites (of daidzein), equol and $O$-desmethylangolensin, over the parent compounds was observed, when compared with the patterns in urine and in faeces. This may be due to the higher isoflavone:metabolite found in plasma compared with urine and faeces (milk is produced by secretory processes of blood). The lower cancer rates in soyabean-consuming populations may thus be due to exposure to isoflavones at the critical developmental period just following birth, via the mother's milk, rather than from adult consumption of soyabean products (Franke \& Custer, 1996; Franke et al. 1998).

Free radicals may play a role in human cancer developments; free radicals have been shown to possess many characteristics of carcinogens (Wiseman \& Halliwell,
1996). Furthermore, membrane function is now understood to be of vital importance to many cellular processes, including the role of membrane enzymes and receptors in cell growth and signalling (Wiseman, 1998). Protection of membrane function against the free radical-mediated process of membrane lipid peroxidation that can result in oxidative membrane damage is clearly important. The reported antioxidant properties of soyabean isoflavones (Wiseman, 1996; Wiseman et al. 1998) could thus contribute to their proposed anti-cancer action. In model membrane systems, the daidzein metabolite equol was a more effective antioxidant than genistein or daidzein itself. Equol had a concentration giving $50 \%$ maximal inhibition of membrane lipid peroxidation of $5 \mu \mathrm{M}$ compared with $30 \mu \mathrm{M}$ for tamoxifen and $8 \mu \mathrm{M}$ for 4-hydroxytamoxifen (Wiseman \& O'Reilly, 1997; Wiseman et al. 1998). Tamoxifen is an anti-oestrogen drug widely used in the treatment of breast cancer and currently being assessed for the prevention of breast cancer (Wiseman, 1994). Plasma values as high as $0.2 \mu \mathrm{M}$ have been reported for equol (Morton et al. 1994), and although this appears to be considerably less than that required in vitro for effective membrane protection against oxidative damage, membrane accumulation in vivo to achieve effective concentrations is likely (see p. 144).

The isoflavones may also exert their protective effects by antagonizing the action of sex hormones and by interfering with cellular signalling mechanisms involving tyrosine kinase (Wiseman, 1996). Phyto-oestrogens demonstrate a structural similarity to the steroid nucleus of the female sex hormone oestrogen, which enables them to bind to oestrogen receptors (and androgen receptors) to produce effects ranging from agonism to antagonism of the endogenous hormone ligand (Miksicek, 1995). The molecular basis of agonism and antagonism at the oestrogen receptor has only recently been elucidated (Brzozowski et al. 1997). Phyto-oestrogens appear to block the growthenhancing effects of oestrogen in the breast, including inhibition of the growth of breast cancer cells. Breast cancer is thought to have a multifactorial causation, ranging from gene profile to diet and lifestyle (Wiseman, 1994). Phytooestrogens can be considered to be acting as anti-oestrogens in the prevention of breast cancer in a similar way to tamoxifen (Wiseman, 1994).

Phyto-oestrogens can also imitate the protective action of oestrogen on the cardiovascular system and on bone. This action may contribute to their reported protective ability against heart disease and osteoporosis, and suggests their use as a natural supplement, as an alternative to hormone-replacement therapy in women (Clarkson et al. 1995). Soyabean protein incorporated into a low-fat diet can reduce cholesterol and LDL and raise $\mathrm{HDL}$, and the oestrogenic isoflavones present are likely to contribute to this effect (Raines \& Ross, 1995). The antioxidant action of phyto-oestrogens may contribute also to their cardioprotective properties. Isoflavones can protect LDL against oxidative modification in vitro. The inhibitory concentration giving $50 \%$ maximal LDL lipid peroxidation for equol was $3 \mu \mathrm{M}$ compared with $15 \mu \mathrm{M}$ for tamoxifen and $1 \mu \mathrm{M}$ for 4-hydroxytamoxifen (Wiseman \& O'Reilly, 1997; Wiseman et al. 1998), and although this is greater than the 
bioavailable level of equol of $0 \cdot 2 \mu \mathrm{M}$ that can be achieved (see p. 143), nevertheless, bioaccumulation into LDL particles and into the lipophilic atheromal plaques associated with the arterial wall is likely, as previously suggested for tamoxifen and 4-hydroxytamoxifen (Wiseman et al. 1993). Indeed, in our own recent dietary intervention study, subjects consumed a soyabean textured vegetable protein product with or without isoflavones (see p. 142), and the biomarkers of oxidative damage measured included plasma isoprostane (a lipid peroxidation product) concentrations (8-epi-prostaglandin $F_{2 \alpha}$, an $F_{2}$-isoprostane, was measured), which showed a significant decrease, and resistance of LDL to oxidation which showed a significant increase (O'Reilly et al. 1998). The increased resistance of LDL to oxidation following consumption of soyabean products is in agreement with other similar studies (Tikkanen et al. 1998). Although total plasma cholesterol and apoprotein $B$ concentrations were unaffected by the isoflavone content of the diet, HDL and apolipoprotein A-I (a novel biomarker of total oestrogenicity) concentrations were significantly higher following the high-isoflavone dietary period (Dean et al. 1998).

\section{Recent developments in bioavailability of flavonoids and phyto-oestrogens: future trends}

The relative bioavailabilities of non-nutrient plant factors in different food sources need to be determined before their exact contribution to the protection of human health can be assessed. Quantitative data for the separate quercetin glycosides of a food could be used to predict the bioavailability of the quercetin in it (Hollman, 1997a; Hollman et al. $1997 a, b$ ). To evaluate the risk:benefit ratio of dietary phyto-oestrogens in human subjects more information is required regarding their bioavailability and the role of gut microflora in modulating bioavailability in both high and low consumers. The differences in response between adults and children clearly need to be elucidated. Soyabean is a major source of dietary phyto-oestrogens, and is widely used in both human and animal feeds. The popularity of soyabean products as meat substitutes has increased markedly over the past decade, with the rise in the popularity of vegetarianism, and this trend is likely to continue. Furthermore, there is increased interest in the use of diets high in phyto-oestrogens to help alleviate menopausal symptoms. More information is needed, however, on the biological effects of increased phyto-oestrogen intake by menopausal women. No simple answers are yet available to the basic uncertainty of the bioavailability of ingested non-nutrient plant factors, including dietary flavonoids and phyto-oestrogens. Research in progress will provide clarification of these important issues within the next 3-5 years.

\section{Acknowledgements}

The Ministry of Agriculture, Fisheries and Food, UK, is thanked for research support.

\section{References}

Adlercreutz CHT, Goldin BR, Gorbach SL, Hockerstedt KAV, Watanabe S, Hamalainen EK, Markkanen MH, Makela TH, Wahala KT, Hase TA \& Fotsis T (1995) Soybean phytoestrogen intake and cancer risk. Journal of Nutrition 125, 757S-770S.

Adlercreutz H (1996) Lignans and isoflavonoids: epidemiology and possible role in prevention of cancer. In Natural Antioxidants and Food Quality in Atherosclerosis and Cancer Prevention, pp. 349-355 [JT Kumpulainen and JT Salonen, editors]. London: Royal Society of Chemistry.

Adlercreutz H, Markkanen H \& Watanabe S (1993) Plasma concentrations of phytoestrogens in Japanese men. Lancet 342, 1209-1210.

Aziz AA, Edwards CA, Lean MEJ \& Crozier A (1998) Absorption and excretion of conjugated flavonols, including quercetin- 4 ' $-\mathrm{O}-$ $\beta$-glucoside and isorhamnetin- $4^{\prime}-\mathrm{O}-\beta$-glucoside by human volunteers after the consumption of onions. Free Radical Research (In the Press).

Bingham SA, Atkinson C, Liggins J, Bluck L \& Coward A (1998) Plant oestrogens: where are we now? British Journal of Nutrition 79, 393-406.

Bowey EA, Rowland IR, Adlercreutz H, Sanders TAB \& Wiseman $H$ (1999) Inter-individual variation in soya metabolism: the role of habitual diet. Proceedings of the Nutrition Society 58 (In the Press).

Brzozowski AM, Pike ACW, Dauter Z, Hubbard RE, Bonn T, Engstrom O, Ohman L, Greene GL, Gustafsson J-A \& Carlquist M (1997) Molecular basis of agonism and antagonism in the oestrogen receptor. Nature 389, 753-758.

Cassidy A (1996) Physiological effects of phyto-oestrogens in relation to cancer and other human health risks. Proceedings of the Nutrition Society 55, 399-417.

Clarkson TB, Anthony MS \& Hughes CL It (1995) Estrogenic soybean isoflavones and chronic disease: risks and benefits. Trends in Endocrinology and Metabolism 6, 11-16.

Cook NC \& Samman S (1996) Flavonoids: chemistry, metabolism, cardioprotective effects and dietary sources. Journal of Nutritional Biochemistry 7, 66-76.

Crozier A, Lean MEJ, McDonald MS \& Black C (1997) Quantitative analysis of the flavonoid content of commercial tomatoes, onions, lettuce and celery. Joumal of Agricultural and Food Chemistry 45, 590-595.

Dean TS, O'Reilly J, Bowey E, Wiseman H, Rowland I \& Sanders TAB (1998) The effects of soyabean isoflavones on plasma HDL concentrations in healthy male and female subjects. Proceedings of the Nutrition Society 57, 123A.

De Vries JHM, Janssen PLTMK, Hollman PCH, van Staveren WA \& Katan MB (1997) Consumption of quercetin and kampferol in free-living subjects eating a variety of diets. Cancer Letters 114, 141-144.

De Whalley C, Rankin SM, Hoult JRS, Jesssup W \& Leake DS (1990) Flavonoids inhibit the oxidative modification of low density lipoproteins by macrophages. Biochemical Pharmacology 39, 1743-1750.

Franke AA \& Custer LJ (1996) Daidzein and genistein concentrations in human milk after soy consumption. Clinical Chemistry 42, 955-964.

Franke AA, Custer LJ, Wang W \& Yang Shi C (1998) HPLC analysis of isoflavonoids and other phenolic agents from foods and from human fluids. Proceedings of the Society for Experimental Biology and Medicine 217, 263-273.

Golbitz P (1995) Traditional soyfoods: processing and products. Journal of Nutrition 125, 570S-572S. 
Hertog MGL, Feskens EJM, Hollman PCH, Katan MB \& Kromhout D (1993a) Dietary antioxidant flavonoids and the risk of coronary heart disease: the Zutphen Elderly Study. Lancet 342, 1007-1011.

Hertog MGL, Feskens EJM, Hollman PCH, Katan MB \& Kromhout D (1994) Dietary antioxidant flavonoids and cancer risk in the Zutphen Elderly Study. Nutrition and Cancer 22, 175-184.

Hertog MGL \& Hollman PCH (1996) Potential health effects of the dietary flavonol quercetin. European Joumal of Clinical Nutrition 50, 63-71.

Hertog MGL, Hollman PCH \& Katan MB (1992) Content of potentially anticarcinogenic flavonoids of 28 vegetables and 9 fruits commonly consumed in the Netherlands. Journal of Agricultural and Food Chemistry 40, 2379-2383.

Hertog MGL, Hollman PCH, Katan MB \& Kromhout D (1993b) Intake of potentially anticarcinogenic flavonoids and their determinants in adults in the Netherlands. Nutrition and Cancer 20, 21-29.

Hertog MGL, Hollman PCH \& Van de Putte B (1993c) Content of potentially anticarcinogenic flavonoids of tea infusions, wines and fruit juices. Journal of Agricultural and Food Chemistry 41 , 1242-1246.

Hollman PCH (1997a) Determinants of the absorption of the dietary flavonoid quercetin in man. $\mathrm{PhD}$ Thesis, University of Wageningen, The Netherlands.

Hollman PCH (1997b) Bioavailability of flavonoids. European Journal of Clinical Nutrition 51, Supp1. 1, S66-S69.

Hollman PCH, de Vries JHM, van Leewen SD, Mengelers MJB \& Katan MB (1995) Absorption of dietary quercetin glycosides and quercetin in healthy ileostomy volunteers. American Journal of Clinical Nutrition 62, 1276-1282.

Hollman PCH, van der Gaag MS, Mengelers MJB, van Trijp JMP, de Vries JHM \& Katan MB (1996) Absorption and disposition kinetics of the dietary antioxidant quercetin in man. Free Radical Biology and Medicine 21, 703-707.

Hollman PCH, van Trijp JMP, Buysman MNCP, van der Gaag MS, Mengelers MJB, de Vries JHM \& Katan MB (1997a) Relative bioavailability of the antioxidant flavonoid quercetin from various foods in man. FEBS Letters 418, 152-156.

Hollman PCH, van Trijp JMP, Mengelers MJB, de Vries JHM \& Katan MB (1997b) Bioavailability of the dietary antioxidant flavonol quercetin in man. Cancer Letters 114, 139-140.

Horn-Ross PL, Barnes S, Kirk M, Coward L, Parsonnet J \& Hiatt RA (1997) Urinary phytoestrogen levels in young women from a multiethnic population. Cancer Epidemiology, Biomarkers and Prevention 6, 339-345.

Karr SC, Lampe JW, Hutchins AM \& Slavin JL (1997) Urinary isoflavonoid excretion in humans is dose dependent at low to moderate levels of soy-protein consumption. American Journal of Clinical Nutrition 66, 46-51.

Keli SO, Hertog MGL, Keskens EJM \& Kromhout D (1996) Dietary flavonoids, antioxidant vitamins and incidence of stroke: The Zutphen study. Archives of Internal Medicine 156, 637-642.

Kelly GE, Joannou GE, Reeder AY, Nelson C \& Waring MA (1995) The variable metabolic response to dietary isoflavones in humans. Proceedings of the Society for Experimental Biology and Medicine 208, 40-43.

King RA \& Bursill DB (1998) Plasma and urinary kinetics of the isoflavones daidzein and genistein after a single soy meal in humans. American Journal of Clinical Nutrition 67, 867-872.

Kirkman LM, Lampe JW, Campbell DR, Martini MC \& Slavin JL (1995) Urinary lignan and isoflavonoid excretion in men and women consuming vegetable and soy diets. Nutrition and Cancer 24, 1-12.

Lampe JW, Karr SC, Hutchins AM \& Slavin JL (1998) Urinary equol excretion with a soy challenge: influence of habitual diet.
Proceedings of the Society for Experimental Biology and Medicine 217, 335-339.

Lapcik O, Hill M, Hampl R, Wahala K \& Adlercreutz H (1998) Identification of isoflavonoids in beer. Steroids 63, 14-20.

Lu, L-JW, Grady JJ, Marshall MV, Ramanujam S \& Anderson KE (1995) Altered time course of urinary daidzein and genistein excretion during chronic soya diet in healthy male subjects. Nutrition and Cancer 24, 311-323.

Lu L-JW, Lin S-N, Grady JJ, Nagamani M \& Anderson KE (1996) Altered kinetics and extent of urinary daidzein and genistein excretion in women during chronic soya exposure. Nutrition and Cancer 26, 289-302.

Miksicek RJ (1995) Estrogenic flavonoids: structural requirements for biological activity. Proceedings of the Society for Experimental Biology and Medicine 208, 44-50.

Morton MS, Matos-Ferreira A, Abranches-Monteiro L, Correia R, Blacklock N, Chan PSF, Cheng C, Lloyd S, Chieh-Ping W \& Griffiths K (1997) Measurement and metabolism of isoflavonoids and lignans in the human male. Cancer Letters 114, 145-151.

Morton MS, Wilcox G, Wahlqvist ML \& Griffiths K (1994) Determination of lignans and isoflavonoids in human female plasma following dietary supplementation. Journal of Endocrinology 142, 251-259.

O'Reilly J, Dean TS, Bowey E, Rowland I, Sanders TAB \& Wiseman $H$ (1998) The influence of dietary isoflavones on markers of lipid peroxidation in healthy male and female volunteers. Proceedings of the Nutrition Society 57, 123A.

Paganga G \& Rice-Evans CA (1997) The identification of flavonoids as glycosides in human plasma. FEBS Letters 401 , 78-82.

Pettersson D, Aman P, Knudsen KEB, Lundin E, Zhang JX, Hallmans G, Harkonen H \& Adlercreutz H (1996) Intake of rye bread by ileostomists increases ileal excretion of fiber polysaccharide components and organic acids but does not increase plasma or urine lignans and isoflavonoids. Joumal of Nutrition 126, 1594-1600.

Raines EW \& Ross R (1995) Biology of atherosclerotic plaque formation: possible role of growth factors in lesion development and the potential impact of soy. Journal of Nutrition 125, 624S-630S.

Reinli K \& Block G (1996) Phytoestrogen content of foods a compendium of literature values. Nutrition and Cancer 26, $123-148$.

Slavin J, Jacobs D \& Marquart L (1997) Whole-grain consumption and chronic disease: Protective mechanisms. Nutrition and Cancer 27, 14-21.

Steinberg D, Parthasarathy S, Carew TE, Khoo JC \& Witzum JL (1989) Modifications of low-density lipoprotein that increase its atherogenicity. New England Journal of Medicine 320, 915924.

Tikkanen MJ, Wahala K, Ojala S, Vihma V \& Adlercreutz H (1998) Effect of soybean phytoestrogen intake on low density lipoprotein resistance. Proceedings of the National Academy of Sciences 95, 3106-3110.

Thompson LU (1994) Antioxidant and hormone-mediated health benefits of whole grains. Critical Reviews in Food Science and Nutrition 34, 473-497.

Williams RL \& Rutledge T (1998) Recent phytoestrogen research. Chemistry and Industry January, 14-16.

Wiseman H (1994) Tamaxifen: Molecular Basis of Use in Cancer Treatment and Prevention. Chichester: John Wiley.

Wiseman H (1996) Role of dietary phyto-oestrogens in the protection against cancer and heart disease. Biochemical Society Transactions 24, 795-800.

Wiseman H (1997) Dietary phytoestrogens: disease prevention versus potential hazards. Nutrition and Food Science 1, 32-38. 
Wiseman H (1998) Phytochemicals (b) Epidemiological factors. In Encyclopedia of Human Nutrition [M Sadler, B Caballero and S Strain, editors]. London: Academic Press (In the Press).

Wiseman H \& Halliwell B (1996) Damage to DNA by reactive oxygen and nitrogen species: role in inflammatory disease and progression to cancer. Biochemical Journal 313, 17-29.

Wiseman H \& O'Reilly J (1997) Oestrogens as antioxidant cardioprotectants. Biochemical Society Transactions 25, 54-59.

Wiseman H, O'Reilly J, Lim P, Garnett AP, Huang W-C \& Sanders TAB (1998) Antioxidant properties of the isoflavone phytoestrogen functional ingredient in soya products. In
Functional Foods, The Consumer, The Products and The Evidence, pp. 80-86 [M Sadler and M Saltmarsh, editors]. Cambridge: Royal Society of Chemistry.

Wiseman H, Paganga G, Rice-Evans C \& Halliwell B (1993) Protective actions of tamoxifen and 4-hydroxytamoxifen against oxidative damage to human low-density lipoproteins: a mechanism accounting for the protective action of tamoxifen? Biochemical Journal 292, 635-638.

Xu X, Harris KS, Wang H-J, Murphy PA \& Hendrich S (1995) Bioavailability of soybean isoflavones depends upon gut microflora in women. Journal of Nutrition 125, 2307-2315. 